\title{
The Influence of Dentin Demineralization on Morphological Features of Cavities Using Er:YAG Laser
}

\author{
Mary A. S. Melo, PhD, Juliana P. M. Lima, PhD, ${ }^{2}$ Vanara F. Passos, PhD, ${ }^{3}$ \\ and Lidiany K. A. Rodrigues, $\mathrm{PhD}^{2}$
}

\begin{abstract}
Objective: The purpose of this study was to evaluate the influence of erbium-doped: yttrium-aluminum-garnet (Er:YAG) laser parameters and different degrees of demineralization on morphological features, diameter, and depth of prepared cavities. Background data: Minimally invasive dentin caries removal has been recommended. Ablation of deep caries lesions using Er:YAG laser should preserve remaining demineralized dentin; however, the influence of the degree of mineralization of this substrate had not been entirely described. Materials and methods: A randomized, factorial design was used to study the effects of two factors. Laser parameter was tested at two levels $(250 \mathrm{~mJ} / 4 \mathrm{~Hz}$ vs. $200 \mathrm{~mJ} / 2 \mathrm{~Hz})$ and degree of demineralization was tested at four levels (control, two-four-eight cycles). Twelve slabs of human dentin were divided into four groups according to the number of cycles induced by pH-cycling: G1, zero cycles; G2, two cycles, G3, four cycles, and G4, eight cycles. An Er:YAG laser was used at an output energy of $250 \mathrm{~mJ} / 4 \mathrm{~Hz}$ and $200 \mathrm{~mJ} / 2 \mathrm{~Hz}$ for all groups, for $10 \mathrm{sec}$ at $12 \mathrm{~mm}$ distance focus/object. Circumference and depth of the cavities were measured on scanning electron microscopy (SEM) images using image analysis software. The mean values were subjected to two way analysis of variance (ANOVA) and Tukey tests. Results: When using $250 \mathrm{~mJ} / 4 \mathrm{~Hz}$, the mean values of circumferential area increased significantly in relation to control $\left(503.54 \mu \mathrm{m}^{2}\right)$ with increasing demineralization level (eight cycles) $\left(555.45 \mu \mathrm{m}^{2}\right)$. Regardless of the demineralization level, there was also significant statistical difference in the studied measurements of the cavities when $250 \mathrm{~mJ} / 4 \mathrm{~Hz}$ and $200 \mathrm{~mJ} / 2 \mathrm{~Hz}$ were used. SEM also showed that laser cavity preparations left no smear layer, and the dentinal tubules were clear. Conclusions: The circumferential area and depth measurements were affected by laser parameter and demineralization level (eight cycles). Energy level output represents a relevant factor for increased circumferential area and depth measurements. High demineralized artificially caries-affected dentin may also imply higher ablation. Appropriated parameter of laser pulse frequency/ power density for demineralized dentin should be used for effective less-invasive caries treatment.
\end{abstract}

\section{Introduction}

D URING THE PAST FEW DECADES, scientific developments in cariology have improved because of an evolution in caries management via a minimally invasive approach. When eliminating a carious lesion, the goal should be to achieve the minimum possible invasion into the crown of the tooth. ${ }^{1}$ The carious dentin removal is an important step in a restorative conservative approach, and the benefits of complete caries removal have been questioned. ${ }^{2,3}$ These lesions have been described as consisting of two distinct layers with different ultrastructural and chemical characteristics. ${ }^{4}$ The outer layer is contaminated with bacteria and should be completely removed during the carious dentin removal. The inner layer is partially demineralized and should ideally be preserved, as it is possible for it to be remineralized because there is only limited collagen degradation. ${ }^{5}$ This particularly layer is less mineralized, and its volume is replaced by water. Therefore, the water content of carious lesions should increase in proportion to demineralization. ${ }^{6}$ This demineralized dentin substrate created at the end of cavity preparation may play a significant role in conservative methods for cavity preparations such as laser irradiation and, subsequently, in the bonding of the adhesive restorative materials to tooth structure. ${ }^{7}$

More conservative approaches, often known as minimally invasive treatments, for deep caries lesions have been adopted, and are becoming more widely accepted in efforts to address a contemporary conservative concept. ${ }^{3}$

Dental lasers for cavity preparation are a conservative approach with some advantages over mechanical drilling

\footnotetext{
${ }^{1}$ Department of Endodontics, Prosthodontics, and Operative Dentistry, University of Maryland Dental School, Baltimore, Maryland.

${ }^{2}$ Post-graduation Program, Faculty of Pharmacy, Dentistry and Nursing, Federal University of Ceará, Fortaleza, Ceará, Brazil.

${ }^{3}$ University of Fortaleza, Fortaleza, Ceará, Brazil.
} 
instruments, such as non-irritation of the sensitive fibers of the pulp, thereby reducing the pain reaction significantly, and ablation free of vibration or pressure that may trigger pain sensation. ${ }^{8}$

Among the laser systems currently available, the erbiumdoped: yttrium-aluminum-garnet (Er:YAG) laser is a widely used dental hard laser, and is considered a safe and effective tool for cavity preparation. ${ }^{9}$ Its wavelengths are absorbed by collagen, hydroxyapatite, and water. ${ }^{7}$ Erbium laser radiation has a great affinity for the water molecule, which is present in quantity in biological hard tissues, especially in carious tissue, where the water content is greater. ${ }^{9}$ The Er:YAG laser irradiation interacts with water to vaporize, resulting in high steam pressure within the lasered tissue. As a consequence, multiple microexplosions occur, which constitute the major principle of Er:YAG laser ablation. ${ }^{10}$ Clinically, the louder characteristic sounds of laser-tissue interaction are intended to alert the dentist when a carious substrate is reached. ${ }^{11}$

Deep demineralized dentin is one of most relevant substrates in clinical practice. Therefore, there is a substantial need for studies pertaining to the influence of Er:YAG lasers for cavity preparation on this substrate. Some studies have pointed out that there is increased ablation of demineralized dentin, as it has high permeability and therefore is moister than the sound dentin. ${ }^{12,13}$ However, we are not certain about the suggested greater ablation on demineralized content of laser-irradiated tissue.

Therefore, the aim of this in vitro study was to evaluate the influence of Er:YAG laser parameters and different degrees of demineralization on morphological features, diameter, and depth of prepared cavities. The null hypothesis was that degrees of demineralization on dentin tissue or laser parameters would have no effect on the morphological features, diameter, and depth of these cavities.

\section{Materials and Methods}

\section{Experimental design and specimen preparation}

This study involved a two by four factorial design. Treatments involved two levels of laser parameters and four levels of degree of demineralization (control, two-four-eight cycles). The variable degrees of demineralization were here obtained by exposing the samples to different numbers of $\mathrm{pH}$ cycling. The variable laser parameter (sound and carious dentin) and variable degrees of demineralization were used, because clinically different areas of dentin within the lesion may present
FIG. 1. Experimental design and analysis realized in this study.

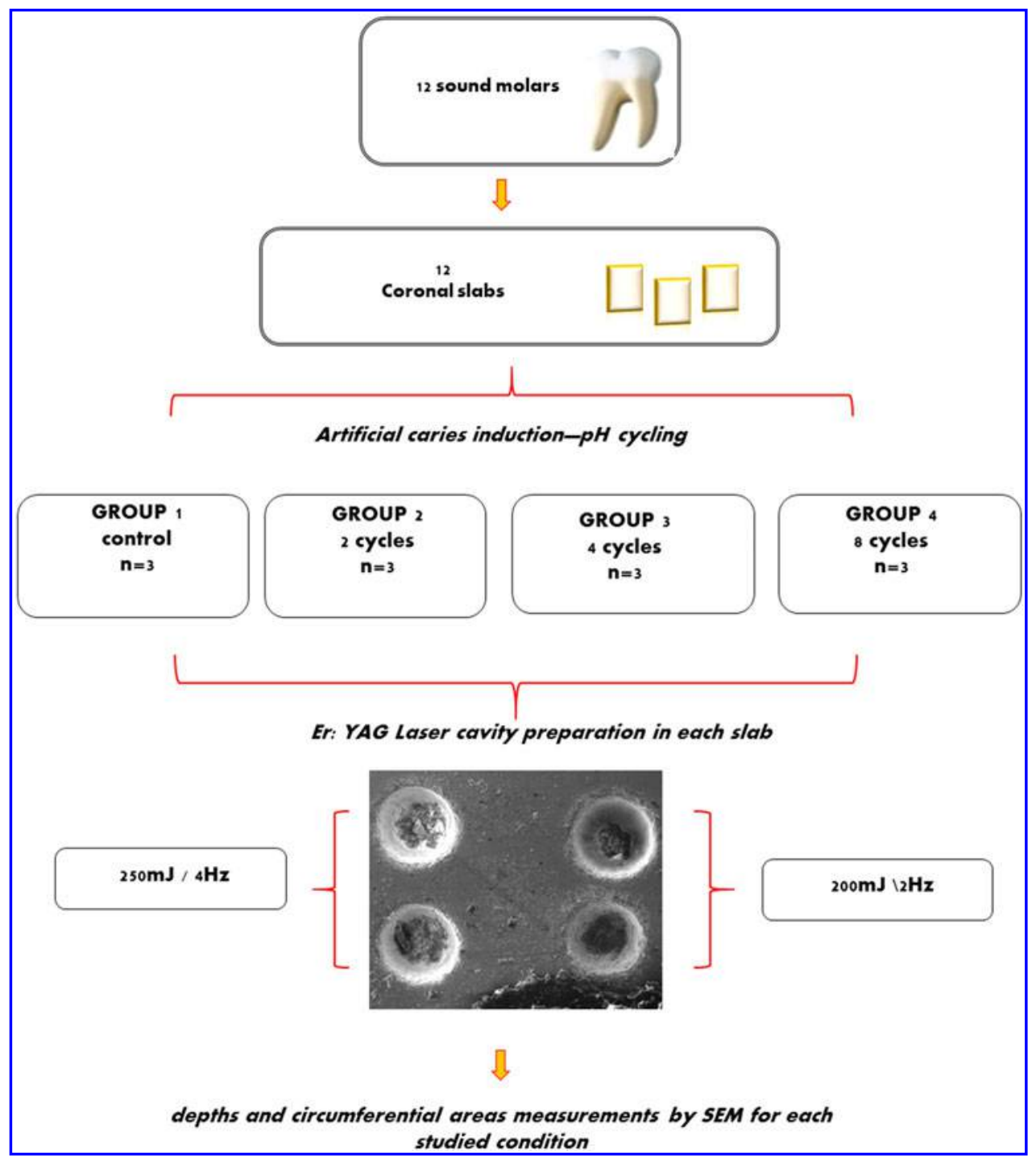


different degrees of demineralization. Figure 1 illustrates the experimental design and analysis realized in this study.

The use of human teeth in this investigation was in conformity with the norms of the local Research and Ethics Committee Medical School (protocol \# 14/2012). Initially, 12 extracted human third molars that had more than two thirds of the formed roots stored in $0.01 \%(\mathrm{w} / \mathrm{v})$ thymol solution at $4^{\circ} \mathrm{C}$ were used.

From these teeth, 12 coronal dentin slabs $(5 \times 5 \times 2 \mathrm{~mm})$ were obtained using a water-cooled diamond saw and a cutting machine (Isomet ${ }^{\mathrm{TM}}$ Low Speed Saw, Buehler, Lake Bluff, IL). The slabs were subsequently finished with watercooled abrasive discs in series (320, 600, and 1200 grit $\mathrm{Al}_{2} \mathrm{O}_{3}$ papers; Buehler, Lake Bluff, IL) and polished with felt paper and diamond spray $(1 \mu \mathrm{m}$; Buehler, Lake Bluff, IL). Only the occlusal dentin face was used, the remaining surfaces of the slabs were protected with resin epoxy adhesive Araldite Hobby 10 min (Brascola, São Bernardo do Campo, SP, Brazil) according to a previous study. ${ }^{14} \mathrm{~A}$ $25 \mathrm{~mm}^{2}$ dentin surface area was exposed to $\mathrm{pH}$ cycling for producing caries-like lesions. The specimens were stored at $4{ }^{\circ} \mathrm{C}$ with $95 \%$ relative humidity throughout the study period in order to avoid dryness of the dentin surface.

To select dentin samples with similar features, the surface microhardness was determined using Knoop hardness numbers (parameters: Knoop diamond, $25 \mathrm{~g}, 5 \mathrm{sec}$ ) (FM 100, Future Tech, Tokyo, Japan). Samples with means values ranging from $48.15 \pm 4.81$ were randomly divided according to a computed aleatorization process into four groups $(n=3)$ : $\mathrm{G} 1$, control, G2, two cycles, G3, four cycles, and G4, eight cycles.

\section{Artificial caries induction: $\mathrm{pH}$ cycling}

Artificial dentin carious lesions were created by a $\mathrm{pH}$ cycling procedure, modified from a previously described protocol. ${ }^{15}$ The dentin slabs were fixed onto the lids of glass container vessels with plastic wire and kept immersed in sterile distilled water. Artificial caries was induced by immersing nine slabs (groups G2-G4) in demineralizing and remineralizing solutions. These slabs were submitted to demineralizing and remineralizing cycles according each protocol group. Each cycle consisted of $4 \mathrm{~h}$ in the demineralizing solution followed by $20 \mathrm{~h}$ in the remineralizing solution. The samples were washed before and after immersion in demineralization solution. The solutions were renewed before the fifth cycle began. The demineralizing solution was composed of acetic acid buffer with $2.0 \mathrm{mmol} / \mathrm{L}$ calcium $\left(\mathrm{CaCl}_{2} \mathrm{H}_{2} \mathrm{O}\right), 2.0 \mathrm{mmol} / \mathrm{L}$ phosphate $\left(\mathrm{KH}_{2} \mathrm{PO}_{4}\right)$, $0.75 \mathrm{~mol} / \mathrm{L}$ acetic acid, and $\mathrm{pH}$ 4.6. The chemical composition of the remineralizing solution was $1.5 \mathrm{mmol} / \mathrm{L}$ calcium, $0.9 \mathrm{mmol} / \mathrm{L}$ phosphate, $0.05 \mathrm{ppm}$ fluoride, $0.15 \mathrm{~mol}$ potassium chloride and $0.1 \mathrm{~mol} / \mathrm{L}$ Tris buffer, $\mathrm{pH} 7.4 .^{16,17}$ This procedure was performed at $37^{\circ} \mathrm{C}$ without agitation.

\section{Laser treatment}

A short-pulsed Er:YAG laser (Key Laser 2, KaVo, Joinville, SC, Brazil) emitting a wavelength of $2940 \mu \mathrm{m}$ was used. The output power and repetition rate of this equipment ranges from 60 to $500 \mathrm{~mJ}$ and from 1 to $15 \mathrm{~Hz}$, respectively. The beam diameter at the focal area for handpiece \#2051 (noncontact) was $0.63 \mathrm{~mm}$. Handpiece \#2051 was indicated to be used for both soft tissue procedures and removal/treatment of mineralized hard tissues. ${ }^{18}$ To ensure consistent spot size, the laser handpiece was fixed in a supported position perpendicular to the dentin surface. A millimeter ruler was used to measure the distance of $12 \mathrm{~mm}$ from the surface to handpiece.

Cavities were performed using the energy depicted on the equipment display and corresponded to the energy delivered by the handpiece $(250 \mathrm{~mJ} / 4 \mathrm{~Hz}$ and $200 \mathrm{~mJ} / 2 \mathrm{~Hz})$ under abundant water spray coolant for $10 \mathrm{sec}(\sim 1.5 \mathrm{~mL} / \mathrm{min})$. These parameters were recommended by manufacturer for ablation of sound dentin $(250 \mathrm{~mJ} / 4 \mathrm{~Hz})$ and primary carious lesions in dentin near to the pulp $200 \mathrm{~mJ} / 2 \mathrm{~Hz}$ ), respectively. ${ }^{19}$ The energies described refer to the energy delivered at the end of the tip, taking into account the transmitting factor (1.0) for this handpiece. The transmitting factor is given by the manufacturer and is depicted in the user manual of the equipment. A power meter Lasermate (Coherent Inc, Santa Clara, CA) was used to measure the maximum output power.

\section{Scanning electron microscopy (SEM)}

All specimens were immersed in modified Karnovsky's fixative solution containing $2.5 \%$ cold glutaraldehyde in $0.1 \mathrm{~mol} / \mathrm{L}$ cacodylate buffer at a $\mathrm{pH}$ of 7.4 for $8 \mathrm{~h}$. The specimens were then dehydrated in a graded series of aqueous ethanol solutions $(70 \%, 85 \%, 95 \%$, and $100 \%$ ethanol) for $10 \mathrm{~min}$ each. The samples were dried overnight at room temperature. They were then mounted on aluminum stubs, sputtercoated with gold/palladium, and examined by a TESCAN SEM (Model VEGA \XMU, Brno, Czech Republic) with different magnifications at an accelerating voltage of $20 \mathrm{kV}$. A set of 4 images from each sample was chosen, yielding 12 images for each condition. To evaluate the surface morphological alterations, circumferential and depth measurements of each microcavity were taken. The irradiated area was crosssectioned perpendicular to the direction of occlusal surface. The depths and circumferential areas were measured using Quantax 800 software (Bruker AXS, Karlsruhe, Germany).

\section{Statistical analysis}

Mean values of measurements were submitted to a two way analysis of variance (ANOVA), and post-hoc Tukey tests were used to compare the effects of the parameter $(200 \mathrm{~mJ} / 2 \mathrm{~Hz}$ vs. $250 \mathrm{~mJ} / 4 \mathrm{~Hz})$ and demineralization level (sound vs. artificially created caries-affected dentin substrates). The software BioStat 2007 Professional (Analyst Soft Robust business solutions company, Vancouver, British Columbia, Canada) was used.

\section{Results}

\section{Measurements of the cavities}

Two way ANOVA revealed that both laser parameter and demineralization level demonstrated a significant effect on the circumferential area of the cavities. The mean values increased with increasing of demineralization cycles of samples in both parameters used, as summarized in Table 1. Figure 2 showed SEM images at $150 \times$ magnification of circumferential measurements of microcavities irradiated with $200 \mathrm{~mJ} / 2 \mathrm{~Hz}$ and $250 \mathrm{~mJ} / 4 \mathrm{~Hz}$ in groups G1, G2, G3, and G4, respectively. When comparing only the variable laser parameter at $200 \mathrm{~mJ} / 2 \mathrm{~Hz}$ subjected to all four substrates, no statistically significant difference among the groups was 
Table 1. Mean ( \pm Standard Deviation) of Circumferential Area and Depth Measurements for All Samples Investigated with the Scanning Electron Microscope After Er:YAG Laser Irradiation

\begin{tabular}{|c|c|c|c|c|}
\hline Parameters & $\begin{array}{l}\text { (G1) Sound } \\
\text { dentin }\end{array}$ & $\begin{array}{c}(G 2) \text { Carious } \\
\text { dentin }(2 \text { cycles })\end{array}$ & $\begin{array}{c}\text { (G3) Carious } \\
\text { dentin (4 cycles) }\end{array}$ & $\begin{array}{c}(G 4) \text { Carious } \\
\text { dentin }(8 \text { cycles })\end{array}$ \\
\hline \multicolumn{5}{|c|}{ Circumferential measurements $\left(\mu m^{2}\right)$} \\
\hline $\begin{array}{l}250 \mathrm{~mJ} / 4 \mathrm{~Hz} / 10 \mathrm{sec} \\
200 \mathrm{~mJ} / 2 \mathrm{~Hz} / 10 \mathrm{sec}\end{array}$ & $\begin{array}{l}503,543.25^{\mathrm{b}, \mathrm{B}} \\
( \pm 10,101.77) \\
416,344.53^{\mathrm{a}, \mathrm{A}} \\
( \pm 42,433.26)\end{array}$ & $\begin{array}{l}426,095.60^{\mathrm{a}, \mathrm{B}} \\
( \pm 30,029.87) \\
391,254.67^{\mathrm{b}, \mathrm{A}} \\
( \pm 19,507.65)\end{array}$ & $\begin{array}{c}448,331.20^{\mathrm{a}, \mathrm{B}} \\
( \pm 26,738.12) \\
405,664.88^{\mathrm{b}, \mathrm{A}} \\
( \pm 7812.25)\end{array}$ & $\begin{array}{l}555,459.70^{\mathrm{a}, \mathrm{A}} \\
( \pm 48,447.31) \\
463,488.65^{\mathrm{b}, \mathrm{A}} \\
( \pm 40,789.58)\end{array}$ \\
\hline \multicolumn{5}{|c|}{ Depth measurements $(\mu m)$} \\
\hline $\begin{array}{l}250 \mathrm{~mJ} / 4 \mathrm{~Hz} / 10 \mathrm{sec} \\
200 \mathrm{~mJ} / 2 \mathrm{~Hz} / 10 \mathrm{sec}\end{array}$ & $\begin{array}{c}1218.83^{\mathrm{a}, \mathrm{A}} \\
( \pm 13.23) \\
599.61^{\mathrm{b}, \mathrm{B}} \\
( \pm 2.51)\end{array}$ & $\begin{array}{c}1083.35^{\mathrm{a}, \mathrm{A}} \\
( \pm 86.64) \\
515.59^{\mathrm{b}, \mathrm{B}} \\
( \pm 10.00)\end{array}$ & $\begin{array}{c}1216.99^{\mathrm{a}, \mathrm{A}} \\
( \pm 21.33) \\
691.03^{\mathrm{b}, \mathrm{B}} \\
( \pm 3.14)\end{array}$ & $\begin{array}{c}1204.34^{\mathrm{a}, \mathrm{A}} \\
( \pm 16.99) \\
630.35^{\mathrm{b}, \mathrm{B}} \\
( \pm 13.25)\end{array}$ \\
\hline
\end{tabular}

The letters next to the values represent statistical analysis performed to all conditions. Different upper case letters in rows indicate significant differences among the groups. Similar lower case letters within columns indicate no statistically significant difference between the parameters.

found $(p>0.05)$. For variable parameter $(250 \mathrm{~mJ} / 4 \mathrm{~Hz})$, a statistically significant difference was found, in which G4 differed from all the other groups.

In relation to depth measurements, there were no statistically significant differences $(p>0.05)$ among all groups when the similar parameters were used; however, a statistically significant difference was found when considering the variable laser parameter $(200 \mathrm{~mJ} / 2 \mathrm{~Hz} \times 250 \mathrm{~mJ} / 4 \mathrm{~Hz})$ in all groups. The depth measurements in all groups at $80 \sim 120 \times$ magnification can be observed in Fig. 3 .

\section{Morphological findings}

The cavities found were round and of very similar depth, with regular and clean-cut margins. According to Lizarelli and Bagnato, ${ }^{20}$ microcavities are divided into three zones: $\mathrm{Z} 1$, center of the microcavity; $\mathrm{Z} 2$, an intermediate zone that may or may not exist; Z3, area unaffected by the irradiation. Intermediate zone was broadly and clearly defined in images from G4 for both laser parameters (Fig. 4A). This may suggest a higher susceptibility of demineralized dentin substrate to laser ablation rate.

When the magnification is $1500 \times($ Fig. 4B), there are virtually no highlighted findings among the samples irradiated with Er:YAG laser at $250 \mathrm{~mJ} / 4 \mathrm{~Hz}$ and $200 \mathrm{~mJ} / 2 \mathrm{~Hz}$. A typical crater-like surface or scaly roughened surface, accompanied by good definition of the exposed orifices of the dentinal tubules, was observed. Vaporization of intertubular dentin is greater than that of peritubular dentin, showing a protrusion of the dentinal tubules with a cuff-like appearance, which was typically noticed.

\section{Discussion}

Cavity preparations and carious dentin removal with Er:YAG lasers are consistent with the principles of minimally invasive preparation. In these processes, the ablative effect of erbium lasers on dental hard tissues can vary according to
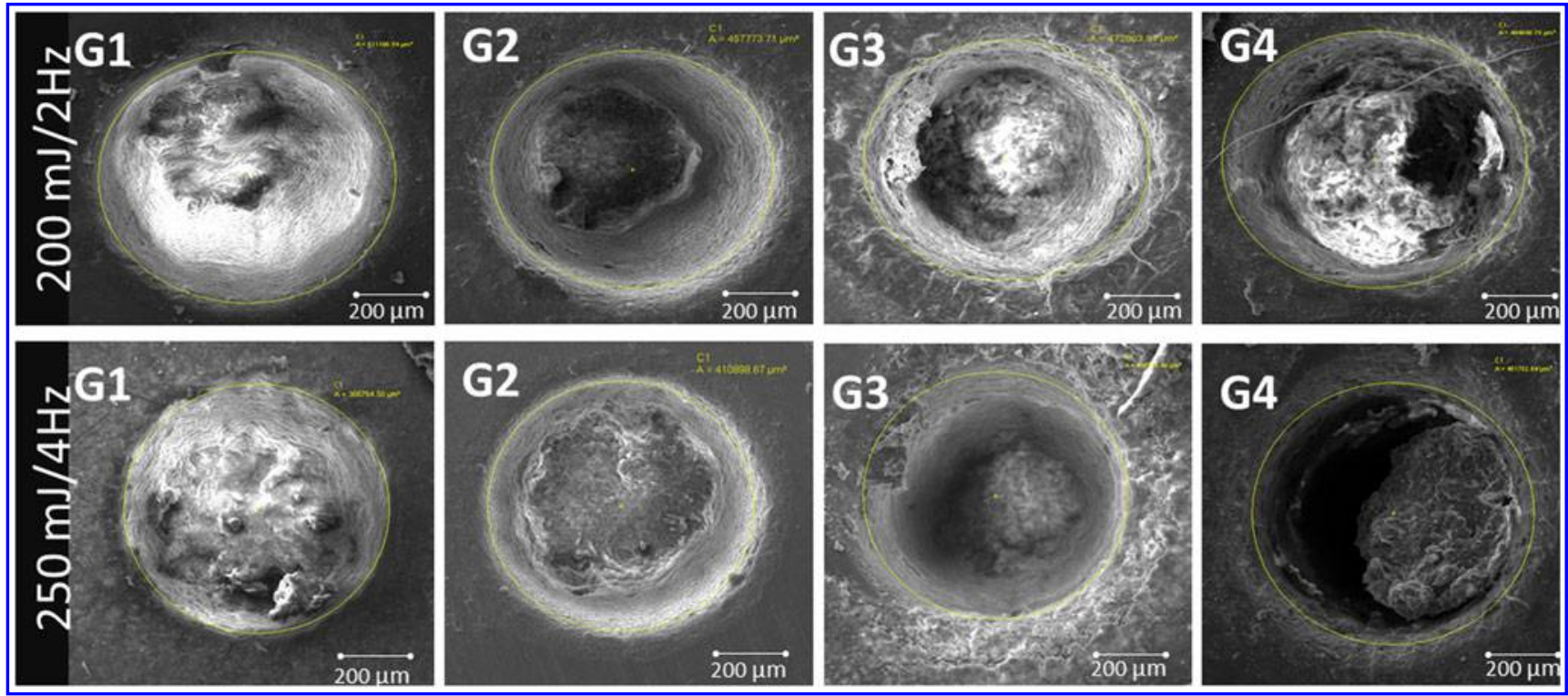

FIG. 2. Circumferential measurements of microcavities irradiated with $200 \mathrm{~mJ} / 2 \mathrm{~Hz}$ and $250 \mathrm{~mJ} / 4 \mathrm{~Hz}$ in groups G1, G2, $\mathrm{G} 3$, and G4, respectively. 

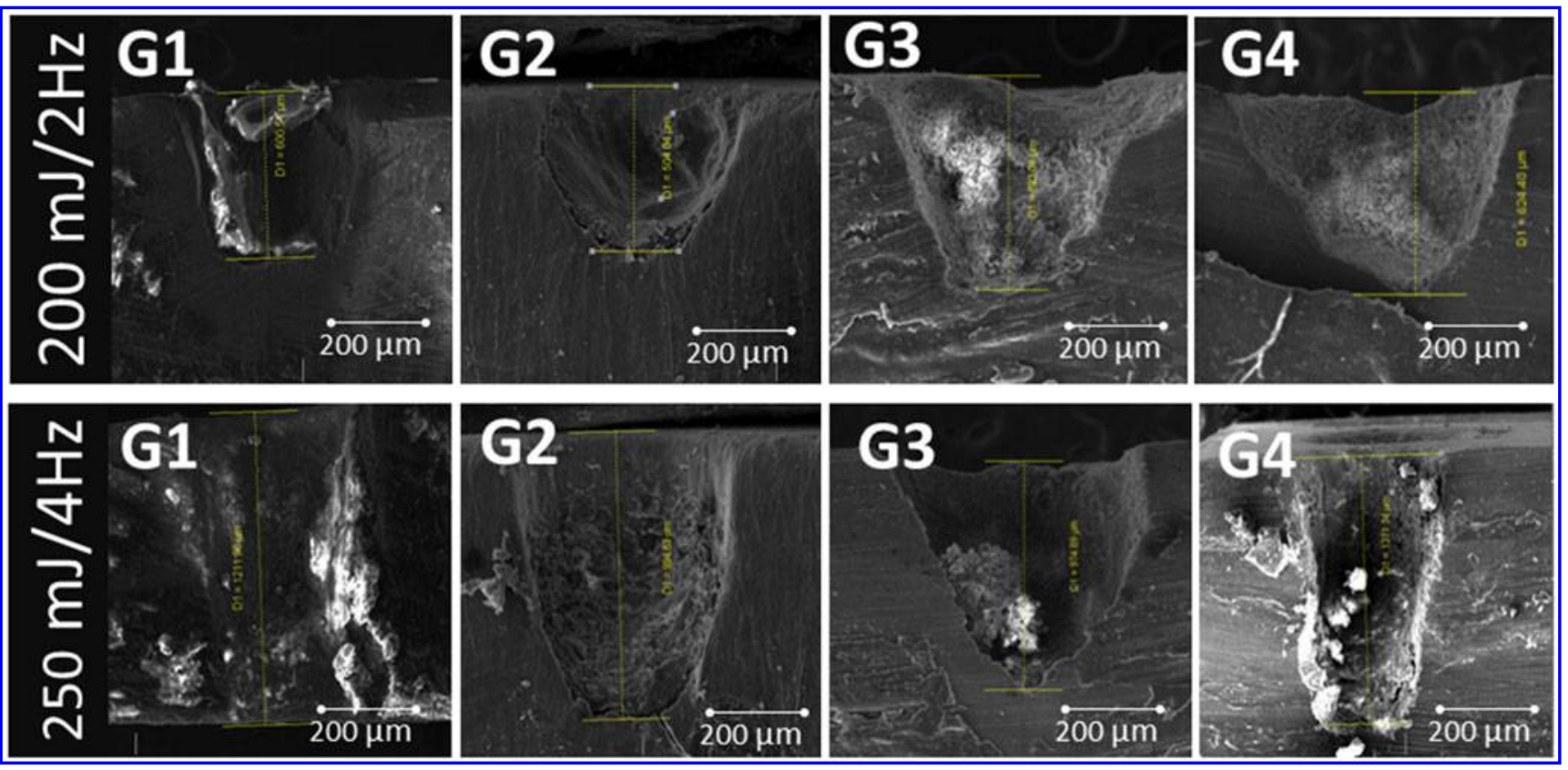

FIG. 3. Longitudinal profiles of microcavities irradiated using $200 \mathrm{~mJ} / 2 \mathrm{~Hz}$ and $250 \mathrm{~mJ} / 4 \mathrm{~Hz}$ in groups G1, G2, G3, and G4, respectively.

the tissue composition and the water concentration. ${ }^{21,22}$ Many morphological studies related to Er:YAG laser and human sound dentin have been published. Nevertheless, not a single study comparing the effects of Er:YAG at different degrees of dentin demineralization has been reported. Results from this study suggest that variation in the water and mineral contents of dentin promoted by demineralization were sufficiently significant to affect the circumferential dimensions of microcavities. The results also expressed the relevant role of laser parameters to demineralized dentin, leading to the rejection of the null hypothesis.

Concerning the dentin demineralized substrate, a $\mathrm{pH}$ cycling model was selected to promote distinctive degrees of dentin demineralization. ${ }^{23}$ The proposed laboratory model was de- signed to mimic the dynamics of mineral loss and gain involved in caries formation, and has been shown to demonstrate accuracy equivalent to that for animal caries. ${ }^{24}$ Other benefits include the high level of scientific control and the resulting lower variability intrinsic to in vitro models, as well as the smaller sample size required. ${ }^{25}$ A recent report by Melo et al. ${ }^{15}$ using this model demonstrated that different numbers of cycles produce dissimilar degrees of demineralization, which was evaluated by cross-sectional hardness testing $(\mathrm{CSH})$ measurements.

The increasing means values for circumferential dimensions with increased demineralized dentin may be explained by a more intense ablation caused by the higher water content of dentin. In our results, when under the same parameter, the slight and moderate demineralization promoted by two and four
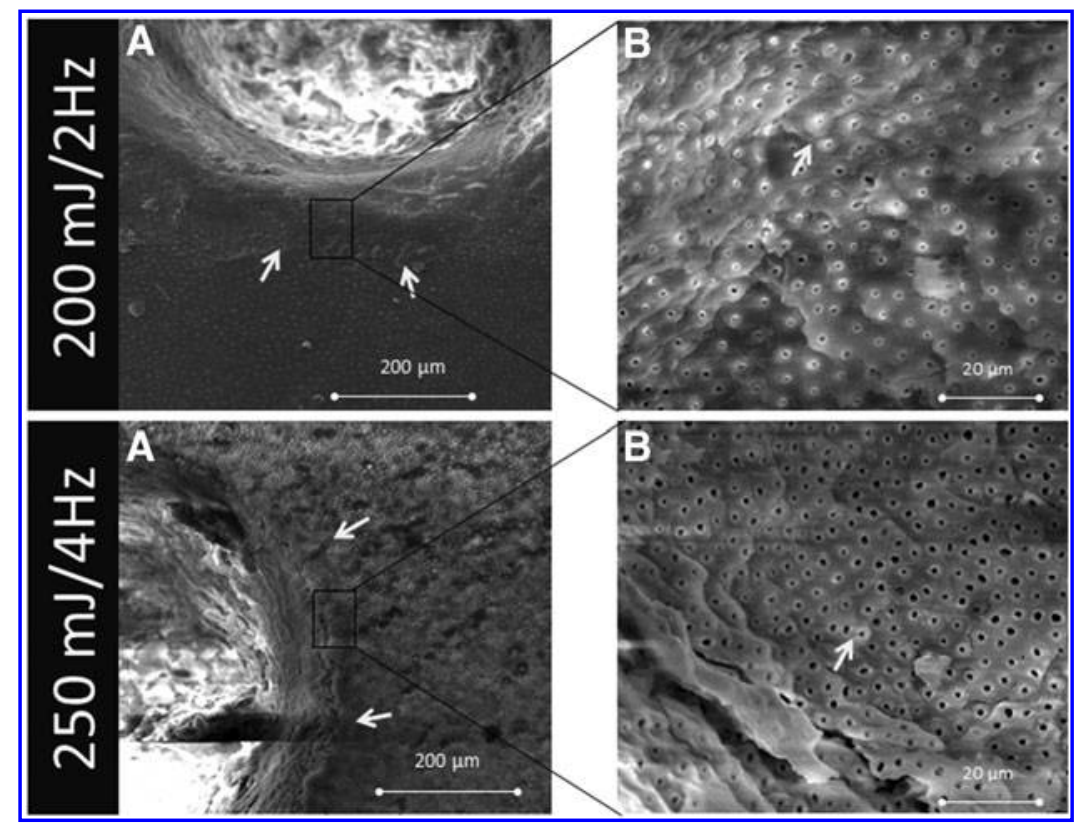

FIG. 4. Scanning electron micrographs of the border of the cavity treated with both parameters used in group G4. 
cycles, respectively, were not able to promote significant alterations in the diametral and depth measurements, showing similar values to those of the control group. This may suggest that deeper lesions (eight cycles), such as those in natural carious dentin, have a much higher water content that may improve the ablation of the tissue. The scarcity of published studies dealing with Er:YAG laser on demineralized dentin substrates makes it difficult to compare the results; however, some previous reports supported these findings for deeply demineralized dentin because of the greater permeability of this substrate compared with sound dentin. ${ }^{26-28}$ Given the exploratory aspect of our study, the sample sizes available for this initial investigation were small, and further investigations using a larger sample size are needed to confirm these results.

The different power and pulse repetition rate applied to demineralized dentin revealed the stronger influence of this parameter on the Er:YAG laser's ablation ability. Although previous studies ${ }^{29-31}$ have attempted to determine Er:YAG laser parameters for carious dentin, the literature is scarce and inconclusive about this. Katleen et al ${ }^{32}$ claimed that energy output $\leq 200 \mathrm{~mJ}$ should be applied using the Er:YAG laser for caries-affected dentin. In the present study, the variable laser parameters based on the manufacturer's recommendations revealed a greater influence than a variable degree of demineralization. The depth and cavities measurements were increased under $250 \mathrm{~mJ} / 4 \mathrm{~Hz} / 10 \mathrm{sec}$. This also confirms the findings of previous investigations that similar effects of laser parameters were also demonstrated. ${ }^{29,33}$ The selected pulse frequency has been also considered the most influential parameter during dentin ablation. ${ }^{34}$ Previous studies by Raucci-Neto ${ }^{35,36}$ showed that the increase of Er:YAG laser frequency provided greater dentin caries removal, in which a larger amount of tissue was removed during irradiation of demineralized substrate, creating a deeper cavity. The use of appropriated parameters of laser pulse frequency/power density for carious substrate should be applied when approaching areas of higher demineralized substrate, such as the inner layers of deep dentin lesions. A nanosecond pulsed laser with a wavelength of $5.8 \mu \mathrm{m}$ also has been suggested for selective removal of demineralized dentin, with minimal damage to sound dentin. ${ }^{37}$

In relation to morphological features, our findings are in agreement with reports in the literature. ${ }^{38,39}$ Open and protruding dentinal tubules were found in human dentinal samples irradiated at $150 \mathrm{~mJ}{ }^{40}$ According to study by Kohara et al. ${ }^{41}$ using Er:YAG laser and $\mathrm{CO}_{2}$, respectively, protruding dentinal tubules are the result of greater ablation of the intertubular dentin as opposed to the peritubular dentin. The intensity and extension of the effects will depend upon the laser parameters: fluence, frequency, and wavelength, as well as the tissue optical and thermal characteristics resulting in specific alterations on the surface according the type of laser applied and the dental tissue irradiated. ${ }^{42}$ In addition, there was no evidence of charring or cracking of dentin using the selected densities. These findings are supported by previous studies of Er:YAG laser irradiation, emphasizing that minimal thermal damage to the surrounding tissues can be expected when a continuous water spray is utilized. ${ }^{43,44}$

\section{Conclusions}

Within the limits imposed in this study, energy level output represents a relevant factor for increased circumfer- ential area and depth measurements of the ablated dentin. High demineralized artificially caries-affected dentin may also imply higher ablation. Appropriated parameters of laser pulse frequency/power density for caries-affected substrate should be used when approaching areas of higher demineralized substrate as a deep layer of dentin lesions. Therefore, further investigations should be undertaken to determine which parameter/protocol should be preferred to yield an optimal conservative outcome for these substrates. Moreover, additional studies should evaluate the bonding performance of current dental materials to different demineralized laser-treated dentin surfaces.

\section{Acknowledgments}

The authors thank IPDI (Institute of Research, Development and Innovation/ Department of Physics, Federal University of Ceará, Fortaleza-CE-Brazil) for SEM measurements, and Jose Bill Rola Junior for providing the Er:YAG laser equipment.

\section{Author Disclosure Statement}

No competing financial interests exist.

\section{References}

1. Banerjee A. Minimal intervention dentistry: part 7. Minimally invasive operative caries management: rationale and techniques. Br Dent J 2013;214:107-111.

2. Mathilde P, McLean ME. Minimally invasive operative care: I. Minimal intervention and concepts for minimally invasive cavity preparations. J Adhes Dent 2001;3:7-16.

3. Ricketts D, Lamont T, Innes NP, Kidd E, Clarkson JE. Operative caries management in adults and children. Cochrane Database Syst Rev 2013;28:CD003808.

4. Zavgorodniy AV, Rohanizadeh R, Swain MV. Ultrastructure of dentine carious lesions. Arch Oral Biol 2008; 53:124-132.

5. Bjørndal L, Kidd EA. The treatment of deep dentine caries lesions. Dent Update 2005;32:402-413.

6. Ito S, Saito T, Tay FR, Carvalho RM, Yoshiyama M, Pashley DH. Water content and apparent stiffness of noncaries versus caries-affected human dentin. J Biomed Mater Res B Appl Biomater 2005;72:109-116.

7. Guven Y1, Aktoren O. Shear bond strength and ultrastructural interface analysis of different adhesive systems to Er:YAG laser-prepared dentin. Lasers Med Sci 2013 [Epub ahead of print].

8. Nguyen D, Chang K, Hedayatollahnajafi S, et al. Highspeed scanning ablation of dental hard tissues with a $\lambda=9.3 \mu \mathrm{m} \mathrm{CO}$ laser: adhesion, mechanical strength, heat accumulation, and peripheral thermal damage. J Biomed Opt 2011;16:071410.

9. Schwass DR, Leichter JW, Purton DG, Swain MV. Evaluating the efficiency of caries removal using an Er:YAG laser driven by fluorescence feedback control. Arch Oral Biol 2012;58:603-610.

10. Liu JF, Lai YL, Shu WY, Lee SY. Acceptance and efficiency of Er:YAG laser for cavity preparation in children. Photomed Laser Surg 2006;24:489-493.

11. Lukac M, Marincek M, Grad L. Dental laser drilling: achieving optimum ablation with the latest generation Fidelis laser systems. J Laser Health Acad 2007;7:1-3.

12. Bachmann L, Diebolder R, Hibst R, Zezell DM. Changes in chemical composition and collagen structure of dentine 
tissue after erbium laser irradiation. Spectrochim Acta A Mol Biomol Spectrosc 2005;61:2634-2639.

13. Clark J, Symons AL, Diklic S, Walsh LJ. Effectiveness of diagnosing residual caries with various methods during cavity preparation using conventional methods, chemomechanical caries removal, and Er: YAG laser. Aus Dent J 2001;46:S20.

14. Melo MAS, De-paula DM, Lima JPM, et al. In vitro photodynamic antimicrobial chemotherapy in dentine contaminated by cariogenic bacteria. Laser Phys 2010;20:1-10.

15. Melo MAS, Goes DC, Moraes MDR, Santiago SL, Rodrigues LK. Effect of Chlorhexidine on the bond strength of a self-etch adhesive system to sound and artificially demineralized dentin. Braz Oral Res 2013;27:218-224.

16. Queiroz CS, Hara AT, Paes Leme AF, Cury JA. pH-Cycling models to evaluate the effect of low fluoride dentifrice on enamel de- and remineralization. Braz Dent J 2008;19:21-27.

17. Guedes S, Melo MAS, Lima JP, et al. Acid etching concentration as a strategy to improve the adhesive performance on Er:YAG laser and bur-prepared demineralized enamel. Photomed Laser Surg 2014 [Epub ahead of print].

18. Almehdi A, Aoki A, Ichinose S, et al. Histological and SEM analysis of root cementum following irradiation with Er:YAG and $\mathrm{CO}_{2}$ lasers. Lasers Med Sci 2013;28:203-213.

19. Handstuck E. User manual, Session 14 (Key Laser 2, KaVo Dental GmbH Vertriebsgesellschaft), 2008:2055-2056.

20. Lizarelli RFZ, Bagnato VS. Dentistry application using a picosecond Nd:YAG. Laser Laser Phys 2003;13:781-758.

21. Li ZZ, Code JE, Van De Merwe WP. Er:YAG laser ablation of enamel and dentin of human teeth: determination of ablation rates at various fluencies and pulse repetition rates. Lasers Surg Med 1992;12:625-630.

22. Yamada Y, Hossain M, Nakamura Y, Suzuki N, Matsumoto K. Comparison between the removal effect of mechanical, Nd:YAG, and Er:YAG laser systems in carious dentin. J Clin Laser Med Surg 2001;19:239-243.

23. Argenta RM, Tabchoury CP, Cury JA. A modified pHcycling model to evaluate fluoride effect on enamel demineralization. Pesqui Odontol Bras 2003;17:241-246.

24. Featherstone JD, Stookey GK, Kaminski MA, Faller RV. Recommendation for a non-animal alternative to rat caries testing. Am J Dent 2011;24:289-294.

25. White DJ. The application of in vitro models to research on demineralization and remineralization of the teeth. Adv Dent Res 1995;9:175-193.

26. Roth KK-F, Duczynski EW. Ablation of healthy and carious enamel and dentin by erbium:YAG laser irradiation. Proc SPIE 1995; 1984:44-51.

27. Toro CV, Derceli Jdos R, Faraoni-Romano JJ, Marchi P, Pécora JD, Palma-Dibb RG. The use of an Er:YAG laser to remove demineralized dentin and its influence on dentin permeability. Microsc Res Tech 2013;76:225-230.

28. Aoki A, Ishikawa I, Yamada T. Comparison between Er:YAG laser and conventional technique for root caries treatment in vitro. J Dent Res 1998;77:1404-1414.

29. Osuka K, Amagai T, Kukidome N, Takase Y, Aida S, Hirai Y. Effect of dentin hardness on ablation rate with Er:YAG laser. Photomed Laser Surg 2009;27:395-399.

30. Armengol V, Jean A, Rohanizadeh R, Hamel H. Scanning electron microscopic analysis of diseased and healthy dental hard tissues after Er:YAG laser irradiation: in vitro study. J Endod 1999;25:543-546.

31. Yildiz E, Sirinkaraarslan E, Yegin Z, Cebe MA, Tosun G. Effect of caries removal techniques on the bond strength of adhesives to caries-affected primary dentin in vitro. Eur J Paediatr Dent 2013;14:209-214.

32. Katleen I, Delmea M, Demanb PJ. Influence of different Er: YAG laser energies and frequencies on the surface morphology of dentin and enamel. J Oral Laser Appl 2006;6:43-52.

33. Colucci V, Amaral FO, Pécora JD, Palma-Dibb RG, Corona SAM. Effects of water flow on ablation rate and morphological changes in human enamel and dentin after Er:YAG laser irradiation. Am J Dent 2012;25:332-336.

34. Brandão $\mathrm{CB}$, Contente $\mathrm{MM}$, De Lima FA, et al. Thermal alteration and morphological changes of sound and demineralized primary dentin after Er:YAG laser ablation. Microsc Res Tech 2012;75:126-132.

35. Raucci-Neto W, Chinelatti MA, Ito IY, Pécora JD, PalmaDibb RG. Influence of Er:YAG laser frequency on dentin caries removal capacity. Microsc Res Tech 2011;74:281-286.

36. Raucci-Neto W, Raquel Dos Santos C, Augusto de Lima F. Thermal effects and morphological aspects of varying Er:YAG laser energy on demineralized dentin removal: an in vitro study. Lasers Med Sci 2014 [Epub ahead of print].

37. Kita T, Ishii K, Yoshikawa K, Yasuo K, Yamamoto K, Awazu K. In vitro study on selective removal of bovine demineralized dentin using nanosecond pulsed laser at wavelengths around $5.8 \mu \mathrm{m}$ for realizing less invasive treatment of dental caries. Lasers Med Sci 2014 [Epub ahead of print].

38. Fontana CR, Malta DAMP, Fontana UF, Sampaio JEC, Bernardes VL, de Andrade MF. Study of the morphological alterations to enamel and dentin in human and bovine teeth after irradiation with Er:YAG laser. Laser Phys Lett 2004;1:411-416.

39. Matsumotoa K, Hossain M, Tsuzuki N, Yoshishige S, Yamada RA. Morphological and compositional changes of human dentin after Er:YAG Laser irradiation. J Oral Laser Appl 2003;3:15-20.

40. Marraccini TM, Bachmann L, Wigdor HA, Walsh Jr. JT, Stabholtz A, Zezell DM. Morphological evaluation of enamel and dentin irradiated with $9.6 \mu \mathrm{m} \mathrm{CO}_{2}$ and $2.94 \mu \mathrm{m}$ Er:YAG lasers. Laser Phys Lett 2005;2:551-555.

41. Kohara EK, Hossain M, Kimura Y, Matsumoto K, Inoue M, Sasa R. Morphological and microleakage studies of the cavities prepared by Er:YAG laser irradiation in primary teeth. J Clin Laser Med Surg 2002;20:141-147.

42. Daskalova A, Bashir S, Husinsky W. Morphology of ablation craters generated by ultrashort laser pulses in dentin surfaces: AFM and ESEM evaluation. Appl Sur Sci 2010; 257:1119-1124.

43. Zhang S, Chen T, Ge L-H. Scanning electron microscopy study of cavity preparation in deciduous teeth using the Er:YAG laser with different powers. Lasers Med Sci 2012; 27:141-144.

44. Hossain M, Nakamura Y, Yamada Y. Ablation depths and morphological changes in human enamel and dentin after Er:YAG laser irradiation with or without water moisture. J Clin Laser Med Surg 1999;17:100-109.

Address correspondence to: Lidiany K. A. Rodrigues Postgraduate Program in Dentistry Faculty of Pharmacy, Dentistry, and Nursing Federal University of Ceará Cap. Francisco Pedro St. Fortaleza, Ceará Brazil

E-mail: lidianykarla@yahoo.com 